\title{
TRES POETAS DEL 27 DESDE SU EXPERIENCIA EXÍLICA: R. ALBERTI, E. PRADOS, J. J. DOMENCHINA
}

\author{
Claude Le Bigot \\ Université de Rennes 2 \\ (ERILAR/CERPI)
}

\begin{abstract}
«Hablar del exilio republicano es otra manera de seguir hablando de la generación del 27»', declaró Ángel González durante el Congreso sobre la generación que se celebró en Cádiz a finales de 1990. Ángel González plantea un problema que no ha suscitado hasta la fecha muchos comentarios en el aluvión bibliográfico que acompaña simposios y relecturas del insigne grupo generacional. La verdad es que los efectos demoladores de tan largo alejamiento del suelo patrio a raíz de la Guerra Civil no ha hecho sino reforzar injustos aprecios que contribuyeron a reducir la nómina de los poetas a las figuras más destacadas (los canonizados por D. Alonso: Diego, Salinas, Guillén, Lorca, Alberti, Aleixandre y Altolaguirre) dejando al margen a otros que los esfuerzos de la crítica, sobre todo universitaria, sacan a la luz sin poder restituirles siempre el rango que se merecían (Bacarisse, Prados, Domenchina, Chabás, Champourcin, Garfias, Hinojosa, entre otros). Las más veces, la historia del grupo se para con la Guerra Civil cuando está claro que mayoritariamente sus componentes siguieron escribiendo desde el exilio sus obras cumbres. Ahora bien, si en la etapa de surgimiento del grupo no resulta tan fácil evidenciar la existencia de una poética colectiva, que de todos modos, estaría ceñida a condicionantes coyunturales, ni el tiempo de la guerra, ni el tiempo del exilio significan una homogeneización de las posturas poéticas. La época de la Guerra Civil no eliminó los clivajes, incluso entre los que compartían sin escatimar esfuerzos el mismo apoyo a la causa republicana. El impacto de la contienda en la producción literaria ha sido paulatinamente integrado en las más recientes
\end{abstract}

1.- Véase A. González, "I.a poesía de la generación del 27", Cuadernos Hispanoamericanos, 514-515, abril-mayo 1993, p. 44. 


\section{TRES POETAS DEL 27 DESDE SU EXPERIENCIA EXÍLICA}

historias de la literatura, aunque a veces a regañadientes ${ }^{2}$. Formular, hoy en día, un aprecio global sobre el destino de la generación del 27 obligaría a superar el examen sucesivo de los casos individuales legitimados por una notoriedad ya consolidada en la preguerra e incluir a las voces incipientes para enmarcar dicha historia de la poesía en el exilio a partir de un planteamiento que admita todos los condicionantes de una poética: situación del locutor y del receptor, permanencia de las tensiones ideológicas, etc. Además, hay que tomar en cuenta el excepcional carácter longevo del exilio que exige por parte del investigador una necesaria periodización. Huelga decir que esta tarea excede el marco de este breve artículo. Sin embargo, el análisis que vamos a presentar se apoyará en el estudio de tres poetas cuyas obras escritas en el exilio demuestran posturas suficientemente diferenciadas en el lapso del primer exilio (1939-1948) ${ }^{3}$. Concretamente, hablaremos de R. Alberti, E. Prados y J. J. Domenchina. Tres destinos poéticos con voz propia, pero que manifiestan tres formas de fidelidad a la poética múltiple del 27.

\section{La doble voz de R. Alberti, entre el clavel y la espada}

Ya en las ansias de la muerte, el desterrado ve un río que arrastra, rota, una puente

R. A.

Si colocamos este primer apartado bajo el lema de un título albertiano, es porque se cifra en él toda la dinámica creadora que rige la poesía exílica de R. Alberti con sus dos modalidades: lírica y combativa. A diferencia de otros poetas para quienes el exilio marca un período de confinamiento, ensimismamiento y marginación, R. Alberti se adapta positivamente a una situación donde la distancia acaba por dar materia a una prolífica tematización. Eso no quiere decir, como lo veremos más adelante, que el poeta no padezca momentos de terrible soledad y angustiadas nostalgias. Pero pronto, a raíz de su salida de España, R. Alberti reanuda la escritura para asomarse a la vida de los refugiados perseguidos por la policía del Ministro del Interior Daladier. Esto dio lugar a un poemario singular por estar salpicado de expresiones francesas que evocan el entorno diario, más bien hostil, en el cual se movían los exiliados republicanos recién llegados. Sobre Vida bilingüe de un refugiado español en Francia, Marie Laffranque dejó constancia de un magnífico trabajo con motivo de la entrega del título de doctor honoris causa a R. Alberti en Toulouse ${ }^{4}$. Tan sólo recordaré que en este libro está en ciernes la solícita preocupación de R. Alberti por sus compañeros de infortunio que representan la España peregrina. Así, surge en tierras de asilo una conciencia aguda de la tarea de divulgación ideológica que les toca a los intelectuales del exilio. De estos esfuerzos saldrán, en el campo de la poesía, dos significativas antologías colectivas, Poetas en el destierro (Santiago de Chile, 1943) y Poetas libres de la España peregrina (Buenos Aires, 1947). Tal iniciativa señala un territorio que no sería abusivo calificar de santuario de resistencia, cruzado por una doble preocupación a la que se suscribe plenamente R. Alberti: la cohesión de la comunidad republicana en el exilio y la malograda suerte de la España cautiva. De modo que

2.- Fuera de las voces ya reconocidas, en su conjunto la poesía del exilio padeció cierto ostracismo, prolongado por opiniones tajantes que le reprochaban su falta de calidad. La insuficiente difusión de la poesía del exilio impidió una opinión fundada. Hoy los textos están a disposición del lector, gracias al inmenso esfuerzo de recuperación llevado a cabo por el grupo de investigadores del GEXEL y sus colecciones de textos; en la misma dirección va la editorial Renacimiento con su colección "Biblioteca del exilio», que edita sin discriminación la obra de los poetas olvidados o semi-olvidados, ofreciendo al público unas opera omnia, rescate indispensable, aunque no se podrá compensar lo definitivamente damnificado.

3.- Llamaré primer exilio a la etapa que va desde el fin de la Guerra Civil hasta los comienzos de la guerra fría.

4.- M. Laffranque, "Rafael Alberti, refugié espagnol", en Dr. Rafael Alberti. El poeta en Toulouse, Toulouse, Université de Toulouse-le-Mirail, 1984, pp. 243-260. 


\section{CLAUDE LE BIGOT}

frente al destierro, la actitud adoptada por Alberti es dictada por la propensión a proyectar su propo destino en el de la colectividad. Una vertiente considerable de la poesía del exilio albertiana se presenta como una prolongación de posturas nacidas al fragor de la contienda o en las luchas políticas de la preguerra. La lucha por la libertad y la democracia guían los principios éticos de R. Alberti. Estas exigencias se agudizan en los momentos esperanzados del año 1945 que marcan el final de la II Guerra Mundial. Desgraciadamente, el franquismo sigue en pie por la voluntad de las potencias victoriosas. R. Alberti no puede silenciar más su indignación cuando escribe «iPueblos libres! ¿Y España?»:

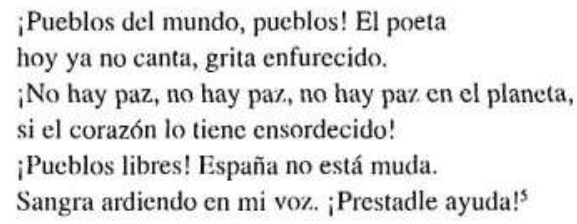

Este poema, sacado de Signos del día, resume las nuevas inquietudes del poeta desde su destierro argentino. Está enterado de lo que sucede en España: sufrimientos, cárceles, ejecuciones, represalias, la imposible paz. Frente a la patria perdida y sumida en tinieblas, Alberti alza su voz acusatoria contra los artífices de la desgracia ("El reloj de Falange", "Nocturno español", "A España vendida"), alza su voz generosa para recordar a los amigos fallecidos ("Retornos de Antonio Machado") o los compañeros de militancia ("A Pablo Neruda", "A Luis Carlos Prestes", "Mano a mano de Nicolás Guillén y Rafael Alberti"). La condición del poeta exiliado es acotada desde una doble perspectiva, ya que la reflexión albertiana no separa lo político de lo literario. Este es el sentido del llamamiento lanzado a los poetas, pintores, escritores de la España Peregrina:

\footnotetext{
Y no penséis, poctas, que por cantar sencillo

el ruiseñor difícil se muere de amarillo.

Si el ruiseñor del pueblo se ahoga en las prisiones,

si en su clara garganta rebosan sus canciones

de libertad y en sangre va su vuelo teñido,

si herido se levanta, si canta perseguido,

joh poetas, oh hermanos de la palabra fuerte!,

no cantar claro dándole la mano es darle la muerte. ${ }^{6}$
}

Tal vez esta actitud tan próxima a todo lo humano explique en Alberti su preferencia por considerar el exilio desde los niveles más concretos: amistades, compañerismo, experiencia sentimental, fraternidad humana. Así que recoge en sus versos todo lo que su condición de "poeta en el siglo» le permite captar. Puede decirse del poeta gaditano que se vuelca hacia afuera buscando el diálogo con los otros en vez de interiorizar el carácter polifacético de su experiencia. De ahí, una variedad de tonos y modalidades, que muestra que el autor no se ciñe a una poética única. Entre el clavel y la espada es el título emblemático que señala una tergiversación impuesta por las circunstancias: cuando imperan la violencia, la tragedia y la muerte, el pocta se somete a las leyes de la ética, y en los tiempos diáfanos prevalecen las leyes de la estética. Este mismo poemario reúne poemas de muy variado cariz y con mezcla de sentimientos contrarios, desde los sonetos acendrados que plasman el escozor del sufrimiento hasta la recia sobriedad de la metamorfosis del clavel en la que el poeta busca ardor y revitalización. El tono elegíaco de "Toro en el mar" desarrolla variaciones sobre el símbolo del toro sacrificado que no dobla la cerviz; el animal varón sintetiza las fuerzas soterradas para insalvables luchas en fusión con el cosmos:

5.- Citamos por la edición de L. García Montero, R. Alberti, Obra completa: Poesía, vol. II, Madrid, Aguilar, 1988, p. 382 .

6.- Op. cit., II, p. 391. 


\section{TRES POETAS DEL 27 DESDE SU EXPERIENCIA EXÍLICA}

Cornearás aún y más que nunca,

desdoblando los campos de tu frente,

y salpicando calles y aldeas

te elevarás de nuevo toro verde.

La representación de las batallas enlaza el recuerdo vivo de la contienda recién apagada con la inquietud ante el cataclismo que se avecina. El sosiego es aparente, la tierra de asilo donde vive el poeta no oculta nuevos temores. De modo que la naturaleza es evocada con su vigor y su fragilidad; ofrece una fugaz esperanza que no puede borrar el dolor y la añoranza. Los símbolos aunados con elementos naturales no se reducen a una interpretación unívoca. Por ejemplo, el árbol desarraigado puede designar las terribles consecuencias del impuesto desplazamiento con la sequedad y la muerte en los momentos de duda y tristeza de Pleamar:

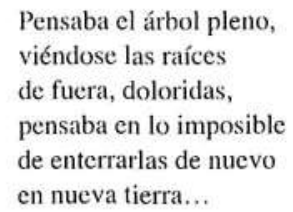

Pero, en otros momentos, incluso en las horas sombrías del primer exilio, cuando R. Alberti evoca a los amigos alejados o muertos para manifestarles gratitud, el árbol cristaliza significaciones más optimistas. Así finaliza su homenaje a Antonio Machado, "De los álamos y los sauces":

Siempre tendrá tu sueño la gloria necesaria:

álamos españoles hay fuera de Castilla;

Guadalquivir de cánticos y lágrimas del Duero.?

La naturaleza ocupa un puesto destacado en los libros del exilio sin que se pueda identificar siempre la referencia; si en Pleamar o Poemas de Punta del Este, se encuentra a veces un referente explícito, en otros muchos casos, los rasgos distintivos del paisaje español suplantan al paisaje americano. Por lo tanto, aquel sigue existiendo pese al alejamiento, y su incontrastable presencia significa la vanidad de los esfuerzos para olvidarlo. La naturaleza no es exactamente un refugio que suministra paz. y sosiego sino un espacio para resarcirse. R. Alberti ve en la naturaleza un espacio de vida libre y de belleza; en ella se produce el misterio de las metamorfosis. Ya apuntaba cl poeta en la sección "Del pensamiento en un jardín" de Entre el clavel y la espada, el goce discreto de quien vuelve a descubrir la vida después de la tragedia colectiva:
Aquí, donde con mano desterrada
y corazón en vuelo hacia castillos
de una ardiente verdad desmantelada,
vivo escuchando el césped e injertando
al rosal rosa mirlos amarillos,
amaneciendo en cuanto voy tocando; ${ }^{10}$

Esta misma sensación se repite en los momentos en que el poeta recupera la confianza. Además, siente que la búsqueda de la belleza puede exigir sus derechos como se observa en una composición más tardía de Poemas de Punta del Este:

No puede, no, no puede la belleza
morir o ser cegada

7.- Op. cit., II, p. 111.

8.- Op. cit., II, pp. 207-208.

9.- Op. cit., II, p. 122.

10.- Op. cit., II, p. 128. 


\title{
CLAUDE LE BIGOT
}

\author{
por cualquier conmoción o cataclismo. \\ Ceñido estoy a veces de catástrofes, \\ con la patria perdida, \\ con mis mares y bosques allá lejos, \\ sin mí, desesperados. \\ Y sin embargo, oh tú, distante, emerges, \\ Venus real de espumas y de hojas. \\ Cuerpo de savias verdes y salitres \\ enamorados subes. ${ }^{\prime \prime}$
}

La obra de exilio de R. Alberti no tiene un rotundo carácter nostálgico; se dejan vislumbrar territorios de felicidad que funcionan como formas de compensación para reapropriarse el mundo. Es posible captar esta configuración de la experiencia exílica a través de varios poemarios de carácter unitario como A la pintura (1945), Retornos de lo vivo lejano (1952), Ora marítima (1953). Las vías de acceso a cierta serenidad ahí trazadas son la pintura, la memoria y el mito. No desarrollaré estos puntos que ya expliqué en otro lugar con motivo de un coloquio sobre el exilio ${ }^{12}$. Quisicra recordar que Retornos de lo vivo lejano está organizado como un tríptico donde Alberti evoca sucesivamente su infancia en el Puerto de Santa María, su encuentro y enamoramiento con María Teresa León, las amistades literarias. El amor y el erotismo ya habían recuperado sus derechos con el "Diálogo entre Venus y Priapo" de rutilantes evocaciones y pinceladas barrocas; tales momentos permiten aliviar el agobio del exilio. La pregunta que se nos ocurre es saber si este trabajo de memoria que permite la escritura tiene capacidad para generar una esperanza, acaso una utopía. Frente a las composiciones de contenido político, el giro que representa Ora marítima es inédito. La bahía de Cadiz ya no es vista a través de los recuerdos de infancia; la cvocacion sale del marco histórico personal para instalarse en el tiempo mítico de los orígenes de hace tres milenios. Al proyectar su destino personal en la remota historia de la fundación de Cádiz, Alberti descubre el poder de la escritura y su capacidad para amalgamar lo que parecía definitivamente escondido: lo próximo y lo lejano, la visible y lo invisible. Si para R. Alberti la poesía permite tender puentes, Ora marítima significa literal y simbólicamente la imagen de la otra orilla anhelada, soñada y rediviva.

Ahora bien, para un hombre de acción, con pasado de militante, como R. Alberti, la posibilidad de volver a España ya se anticipa a través de su compromiso con el pueblo y la invención de Juan Panadero es lo que permite mejor salvarse de las distancias. Con las Coplas de Juan Panadero (1949-1953), Alberti manifiesta su preferencia por la forma breve de los cantares populares. Con esta actitud, el poeta se plantea la cuestión de la recepción y opta por escribir una poesía para la inmensa mayoría, expresiva, sobria y directa, inmediatamente identificable por el oído popular, en forma de tercetos octosílabos o soleares. Adoptando esta forma inspirada en el folklore, el poeta tiende a diluir su propia personalidad en una especie de voz anónima. Al trocar su identidad por la de Juan Panadero quiere hacerse el portavoz de los humildes, que anhelan saciar su sed de justicia. Pese a esta decantación formal, algunos motivos recuerdan la situación personal de Alberti cuando tributa un homenaje a Pablo Neruda o a la Pasionaria. Domina el tono incisivo, mordaz y panfletario; sin embargo, en algunos momentos, la composición puede expresar una tensa emoción como en la muerte del desterrado:

Ya en las ansias de la muerte,

el desterrado ve un río

que arrastra, rota, una puente. ${ }^{13}$

11.- Op. cit., II, p. 477.

12.- Véase "L.es émergences du retour dans la poésie de R. Alberti", en L'émigration: le retour.

13.- Op. cit., II, p. 575. 


\section{TRES POETAS DEL 27 DESDE SU EXPERIENCIA EXÍLICA}

Los símbolos más sencillos no carecen de eficacia, y el que los maneja muestra su capacidad para asimilar los rasgos distintivos de la poesía popular: sencillez, espontaneidad, plenitud expresiva, humorismo ${ }^{14}$. Este tipo de poesía no dejó de levantar críticas por su facilidad. El resto de la producción albertiana basta para apreciar la maestría del poeta. Y los presuntos fallos no son más que los límites inherentes al género que va subordinado estrechamente con la actualidad, que practica cierto esquematismo, que no evita los desmanes de la diatriba. Pero aislar esta producción lleva forzosamente a un aprecio parcial de la producción de exilio de Alberti.

\section{Emilio Prados, la voz en busca de su centro}

Soledad tú me diste

Sin ser voz mi palabra.

E. P.

Sin querer buscar un anticipo premonitorio de su derrota interior en la obra de antes de la guerra, no es inútil recordar que Emilio Prados había superado períodos de crisis espiritual mediante la entrega a la causa colectiva en defensa del pueblo agredido durante la rebelión de Asturias en 1934. El producto de esta toma de conciencia se volcó en los romances de Llanto en la sangre. La Guerra Civil había de prolongar esta fase de compromiso, aunque el poeta dejaba sitio a una poesía más meditativa, de corte metafísico en las mismas páginas de Hora de España. El exilio en México comienza como para muchos desterrados por un tiempo de desconcierto que en el caso de Prados corresponde a un desahogo con el cual abandona una poética de compromiso social colectivo que le mermaba su vocación de poeta meditativo. En una luminosa ponencia, Francisco Chica avanza a medias palabras la hipótesis de que Prados pudo haber deshechado toda su producción comprometida : «Confundido el verdadero alcance de su protesta, Prados detestaría a la larga esta parte de su obra que condicionada por el eco social que alcanza se le aparece como una huida de su destino real» ${ }^{15}$. Cuando otros poctas seguían manteniendo su fe en la militancia (Alberti, P. Garfias, Juan Rejano), cuando otros volvían sobre las andadas reanudando con un neo-clasicismo (Domenchina, Salinas, Quiroga Plá), E. Prados pertenece a un grupo que alcanza voz independiente y madurez con el exilio.

A la hora de asomarnos a la imponente producción pradiana, creemos que acierta Víctor García de la Concha cuando declara : «Descartaremos una lectura limitada a la circunstancia del desterrado» ${ }^{16}$. Una característica que diferencia la poesía pradiana de la de sus compatriotas desterrados es la casi ausencia de añoranzas de España. Unas pocas composiciones aluden al tiempo anterior al exilio con referencias explícitas a un paisaje español con los "olivos", los "toros", el "barbecho" (véase "Cuando era primavera en España", Penumbras $\mathrm{I}^{17}$ ). En el mismo libro no se ignora tampoco el paisaje mejicano, pero éste enlaza con paisajes interiorizados y por venir:

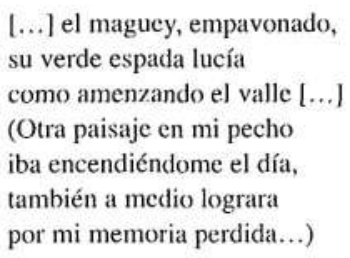

\footnotetext{
14.- Sobre esta cuestión, hay que consultar el artículo de Yvan Lissorgues, "La poética de Juan Panadero", en Dr: Rafael Alberti, op. cit., pp. 185-205.

15.- F. Chica, "El silencio activo: poesía y pensamiento en la obra mexicana de Emilio Prados", en Rose Corral y otros, Poesía y exilio. Los poetas del exilio español en México, Colegio de México, 1995, p. 74.

16.- V. García de la Concha, La poesía española de 1935 a 1975, Vol. 1. Madrid, Cátedra, 1987, p. 299.

17.- Citamos por la edición Emilio Prados, Poesías completas, México, Aguilar, 1975, 2 vols.
} 


\section{CLAUDE LE BIGOT}

Lo dicho entre paréntesis muestra la pugna entre recuerdos de contornos difuminados y la espera de un nuevo horizonte indefinido aún, de difícil acceso, pero con fucrte atractivo por su belleza. De momento, el poeta sólo percibe la necesidad de buscar en su propia soledad las raíces de su ser:

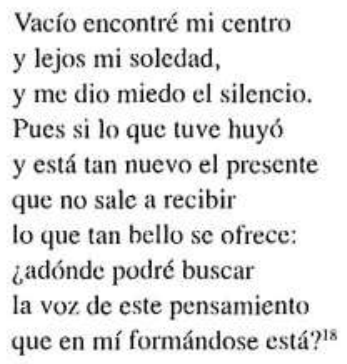

Este viaje ontológico obliga a una tremenda lucidez, un radical ascetismo para desvincularse de todos los incentivos materiales e inventarse una nueva fe en el hombre, fuera de las antiguas ataduras: llámense Dios, Razón, Idea o Ser Supremo. El método parece inspirarse en la duda cartesiana; la pervivencia y resistencia del pensamiento frente a los embates de la existencia fortalecen al poeta en su convicción de que pensarse es nacer:

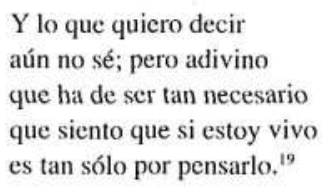

El poema XIX de Penumbras, ya citado varias veces, ofrece un avance suficientemente claro de las ideas rectrices del pensamiento pradiano: como no es posible hablar del ser, el poeta intentará expresar los lugares donde palpita el ser, las moradas del ser que anida en el silencio, el misterio, los recovecos de la vida.

Tempranamente en su exilio, Prados intuye que su salvación pide una refundación de sus orígenes: un des-nacer. Pero la construcción de una identidad propia en un plan existencial sólo nos interesa en tanto que se vierte en lenguaje poético. De Mínima muerte a Jardín cerrado, Prados construye una obra tan rigurosa como el Cántico guilleniano, con carácter tal vez más repetitivo en los temas y motivos que ilustran $\mathrm{el} \mathrm{armazón} \mathrm{conceptual.}$

Entre los temas preferentes de E. Prados están la soledad y la memoria. Pero nos consta que no son temas exclusivos del exilio; que se habrán de considerar como territorios regentados por leyes filosóficas acerca del lenguaje y del taller conceptual. En Mínima muerte, se configura la paradoja de la soledad fecunda. Ocurre que el poeta propone la comparación aclaradora, la que echa luz sobre su condición de hombre que busca a tientas su amor a la vida. La imagen del hueso preso en la fruta alegoriza el dinamismo de la materia orgánica en su oposición interior/exterior, y más allá en su ciclo deterioro/renucvo:

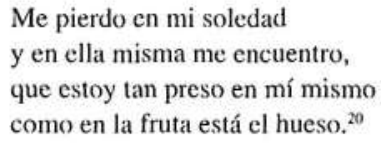

18.- Op. cit., vol. I. p. 781.

19.- Ibidem.

20.- Op. cit., vol. I. p. 804. 


\section{TRES POETAS DEL 27 DESDE SU EXPERIENCIA EXÍLICA}

El mismo juego tensional articula la segunda sección de Mínima muerte, titulada "Trinidad de la rosa". Prados establece la homología entre «la rosa y el hombre» para mostrar que, igual que el hombre, la flor nos maravilla por su existir hacia fuera (cromatismo, fragancia y belleza).

Con Jardín cerrado, E. Prados da a conocer un libro de hondas reflexiones, de carácter unitario ya que viene fuertemente articulado en cuatro secciones que describen un itinerario espiritual por el jardín -no tanto el hortus conclusus renacentista sino un territorio de reconciliación con sí mismo- mediante una dialéctica plenamente asumida entre vida y muerte. Los subtítulos marcan las etapas para llegar a la serenidad: «el jardín perdido», «el dormido en la yerba», «umbrales de la sombra», "Meditaciones al margen de un jardín», "la sangre abierta», "Vuelta y perennidad en el jardín del cuerpo». El jardín perdido de Prados rebasa la trillada idea del edén perdido para designar metafóricamente las «ansias de transfiguración del hombre» como lo señala Juan Larrea en un magnífico prólogo que escribió en 1948 para saludar la novedad y hondura del poemario. Pues el jardín cerrado es el hombre hecho cuerpo sin la dicotomía que la mayoría de las religiones han impuesto, la metáfora viene explicitada en el "Cantar del dormido en la yerba":

$$
\begin{aligned}
& \text { La muerte está conmigo; } \\
& \text { mas la muerte es jardín } \\
& \text { cerrado, espacio, coto, } \\
& \text { silencio amurallado } \\
& \text { por la piel de mi cuerpo; } \\
& \text { donde, inmóvil -almendra } \\
& \text { viva, virgen-, mi luz } \\
& \text { contempla y da la imagen } \\
& \text { redimida, del fuego. }{ }^{21}
\end{aligned}
$$

Las posturas adoptadas por Prados no se confunden como se lee muy a menudo con una vuelta al misticismo. En él, se da una visión unitaria del hombre, porque se seculariza definitivamente el principio que le presta vida. De modo que la ruptura afectiva y sentimental que representó cl exilio quedó en la poesía pradiana diluida en su capacidad a proyectarse en el mundo, extendiendo los límites de la soledad. En los poemas de "Umbrales de sombra", E. Prados escribe:

$$
\begin{aligned}
& \text { Por temor a la muerte o al olvido, } \\
& \text { rompí la caja que me dio la vida } \\
& \text { y sin cuerpo nací; que era yo el mundo, } \\
& \text { su gracia y su razón y aún su conciencia. }{ }^{22}
\end{aligned}
$$

El último poema de Jardín cerrado, "El cuerpo en el alba" deja aparecer después de las sucesivas muertes del poeta una posible cpifanía:

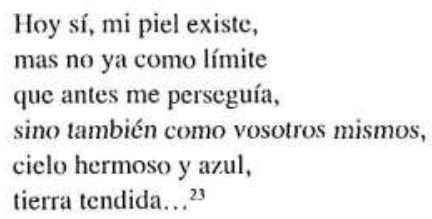

En un reciente libro de Michel Deguy, el poeta filosófo declara: «Quand la perte de tout espoir survient, la question est en quoi transformer cette perte ${ }^{24}$. La experiencia exílica de Prados describe una secuencia que encaja con el siguiente esquema: la pérdida, el abandono de la

21.- Op. cit., vol. II, p. 99.

22.- Op. cit., vol. II, p.203.

23.- Op. cit., vol. II, p 353.

24.- M. Deguy, L'énergie du désespoir, Paris, PUF, 1998, p. 47. 


\section{CLAUDE LE BIGOT}

utopía como avatar de la esperanza, y por fin la transmutación de lo perdido en un resurgimiento hacia una nueva entelequia. "El cuerpo en el alba" en sus últimos versos, instando a que no se lean como ecos de misticismo, sino experiencia del vacío que compendia a mi parecer el prometéico esfuerzo de Prados para salir adelante:

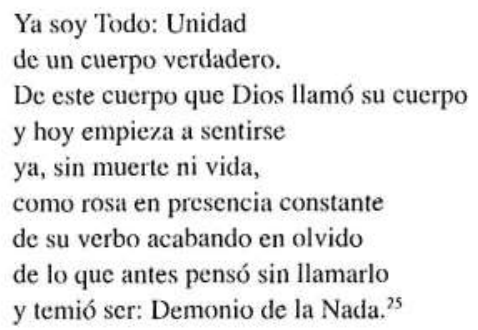

La sucrte le deparó a Prados construir una poética bastante alejada de la de su generación; y eso a pesar de una forma que mantiene firmes los moldes más usados por el grupo aunque hay en el corpus pradiano del primer exilio una presencia masiva del romance, de las coplas, las seguidillas, las cancioncillas, y muy excepcionalmente la forma breve alterna con el ritmo amplio de los versos de arte mayor. Lo que sí parece nuevo y orienta la poesía de Prados hacia nuevos derroteros es la invención de un decir que acude permanentemente a la paradoja, la antítesis, de manera a la vez seria y juguetona. La humildad de la copla popular no cohibe en él la expresión de un atormentado pensamiento que halla en los escondrijos del concepto una voz lírica absolutamente moderna.

\section{La voz ensimismada de Juan José Domenchina}

...tan roto en tu existir

J. J. D.

Se tardó mucho en reconocer la voz peculiarísima de Juan José Domenchina en la producción del exilio español, pese al volumen no despreciable de una serie de poemarios que vieron la luz. entre 1940 y 1950 (Destierro, Pasión de sombra, Tres elegías jubilares, Exul umbra, La sombra desterrada). Como consta en las cartas que mandaba Domenchina desde México a Vicente Aleixandre, éste no ocultaba la entrañable emoción y el fuerte cntusiasmo que le había ocasionado la lectura de aquella poesía del destierro ${ }^{26}$. Pero, el contexto histórico español no permitió que la obra domenchiniana tuviese el merecido interés; por lo tanto, parece legítimo que la actual investigación intente rehabilitar a un poeta que la historia vincula sólo a trechos con el grupo del 27.

Acaso los primeros en llamar la atención sobre el lugar destacado ocupado por Domenchina en la poesía del destierro fueron los mismos compañeros de infortunio desde diversas procedencias. Concha Zardoya, la pionera, y más tarde el infatigable amanuense y sagaz. crítico del exilio que fue Manuel Andújar. La primera insistió en el motivo de la sombra que desarrolló J. J. Domenchina hasta el punto de convertirlo en una poética de la enajenación ${ }^{27}$, como lo veremos a continuación. Por su lado, Andújar recalcó en las añoranzas impuestas por el imposible regreso a la España perdida. Tal situación vivida, las más veces con un sentimiento de total injusticia, ha generado en J. J. Domenchina tres actitudes existenciales que configuran la experiencia exílica del autor, a saber: sus nostalgias castellanas y madrileñas, su percepción

25.- Emilio Prados, Jardín cerrado, op. cit., p.

26.- Véase el epistolario editado por Amelia de Paz: Vicente Alcixandre, Dámaso Alonso, Gerardo Diego y Jorge Guillén, Cartas a Juan José Domenchina, Málaga, Centro Cultural de la Generación del 27, 1997.

27.- C. Zardoya, "Juan José Domenchina, poeta de la sombra", Revista Hispánica Moderna, XVI, 1950, pp 123129. 


\section{TRES POETAS DEL 27 DESDE SU EXPERIENCIA EXÍLICA}

de la precariedad de la vida, su voluntad de fundamentar en su propia soledad una razón de vivir. En todo esto se observarán puntos comunes con otros poetas exiliados, pero también una personalísima diferencia en cuanto a la consecución de una $\mathrm{vOz}_{\text {p }}$ propia dentro del grupo generacional.

Donde las nostalgias de la tierra nativa cobran el relieve más nítido y directo es la serie "Burlas y veras castellanas" (Destierro, 1942). Siguen surgiendo como brotes de contemplación estampas mesetarias con sus retahilas de mulas, bregas campesinas, capeas rurales, paisajes cruzados por adustos labradores, pueblos donde la recia dignidad roza el burdo cotilleo. Juan José Domenchina entrega, con talento y buen tino, engarzado en elegantes "soledades" un compendio de fervoroso españolismo. Si se percibe en estos medallones un claro antecedente machadiano, Domenchina matiza la gravedad del maestro poniendo a sus retratos rasgos de socarronería. Pero donde coinciden ambos poetas es en la percepción de la parquedad de palabras que manifiesta el temple castellano, como se nota en el poema que encabeza la serie "Burlas y veras castellanas":

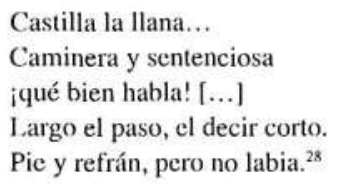

Aunque con el tiempo se irá decantando el tajante perfil castellanista, Domenchina nunca callará sus intensas nostalgias. Mejor dicho ganará su voz en preñadas emociones al evocar con la refinada pasticidad que permite el soneto la «luz caliente» y «el sol que acrisola...», «la llanura interminable» ${ }^{29}$, el «lúcido frío de Madrid $»^{30}$, «el azul de oro entre las nubes blancas de Castilla» ${ }^{31}$. Desde estas trémulas remembranzas vueltas hacia una España lejana y añorada, Domenchina apenas otorga presencia a la tierra que con generosidad lo acoge. Tan sólo huidizos y breves apuntes, con algo de chisporroteo juguetón, acotan una tierra de asilo que no da lugar a ninguna clase de apropiación sino atisbos de mala conciencia, intuyendo además que México le dará sepultura como en este testamento ológrafo fechado en el 18 de enero de 1944:
...Y sépase que yo, viejo cristiano rojo, de limpia sangre azul, vecino de Madrid, y residente peregrino aquí, en Tenochtitlán - postcortesiano
imperio gachupín del lucro indiano-, otorgo borrador de mi interino testamento fatal, en paladino romance, por mi gusto y por mi mano. ${ }^{32}$

Siempre J. J. Domenchina habrá pensado que su estancia en ticrra mejicana era un tránsito hacia una etapa, no de senectud sino de interminable expiación. Esto es el significado del emocionante via crucis cuyas estaciones quedaron pulcramente plasmadas en el patético itinerario espiritual

28.- J. J. Domenchina, Obra poética, ed. de Amelia de Paz, Madrid, Castalia, 1995, vol. 2, p. 43. Citamos por esta edición.

29.- "Aquel aire cernido, transparente", op. cit., n 589, p. 222. Por comodidad de localización, indicamos la numeración adoptada por Amelia de Paz, en su edición antecitada.

30.- "Radiante frío de diamante: enero", op. cit., n 517, p. 105.

31.- Op. cit., $\mathrm{n}^{\circ} 589$.

32,-Op. cit., $\mathrm{n}^{\circ} 497$, p. 94. 


\section{CLAUDE LE BIGOT}

cifrado día tras día en Pasión de sombra ${ }^{33}$. En un gesto de autocontemplación, el pocta se reconoce como un ser en agonía, hundido en la incertidumbre de un presente tambaleante. La imagen del camino - tan trillada como metáfora del destino- cobra aquí nuevo vigor como expresión de una pugna entre libertad y destino. Escribe Domenchina:

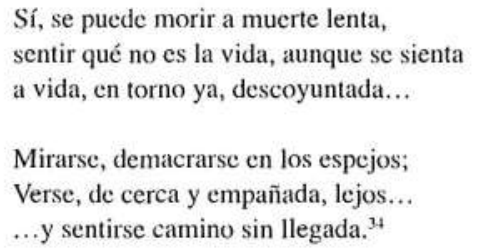

Con Pasión de sombra, el autor se somete a una lúcida introspección dictada por una única preocupación: el punzante dolor nacido de un prolongado exilio. Si el poeta no se demora en las causas que generaron su destierro, afloran en algunos momentos acentos satíricos para denunciar lo morboso y lo tétrico que regentan la vida de la España cautiva:

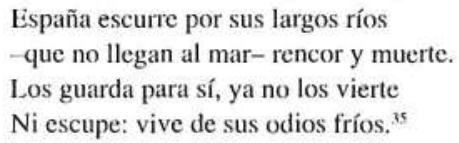

Esta visión crítica no constituye el tema axial del libro pero señala con suficiente claridad y tono acusatorio qué bando trajo «la ignominiosa muerte» ( $\left.n^{\circ} 518\right)$. Para hablar de la España interior, Domenchina se inventa unos supuestos fragmentos de carta, de donde no puede surgir ningún consuelo sino al contrario razones para sentirse más alejado. Esto ya aclara la magnitud de la desgracia tanto individual como colectiva.

Ante semejante catástrofe, el pocta se siente inerme, va perdiendo las asideras que garantizaban cierto grado de cohesión social dentro de la comunidad exiliada. La imagen del camino, tan frecuentemente usada por Domenchina, enseña con creces la situación precaria de un individuo extraviado, desnortado, abocado a un porvenir errático, y en última instancia vaciado de su humana sustancia:

\footnotetext{
No mides el camino: es el camino

el que te mide y lleva en tus pisadas.

Tienes horas de tedio, prorrogadas

en minutos de angustia y desatino[...]

No estás en donde estás, que te quitaron

tu sitio, y ya no hay sitio que sustente

las pisadas por dar que te quedaron. ${ }^{36}$
}

La imagen del camino es recurrente en toda la poesía de exilio de Domenchina, y recibe un tratamiento personal si cotejamos con el uso que hicieron del camino otros dos poetas: Antonio Machado en una perspectiva más optimista o el León Felipe de Versos y oraciones de caminante desde una postura afín a la inseguridad y la angustia de Domenchina. Viene completando la imagen

33.- Los poemas reunidos bajo este rótulo llevan por título la fecha de su composición. Este diario íntimo apunta los «sentimientos dolorosos sufridos durante tres largos meses de noche de insomnio entre el 9-III-1943 y el 9-III1944 », en G. Bellver, El mundo poético de Juan José Domenchina, Madrid, Editora Nacional, 1979, p. 118.

34.- Op. cit., $\mathrm{n}^{\circ} 510$, p. 101.

35.- Op. cit., $\mathrm{n}^{\circ} 519, \mathrm{p}, 106$.

36. Op. cit., $\mathrm{n}^{\circ} 531$, p. 113. 


\section{TRES POETAS DEL 27 DESDE SU EXPERIENCIA EXÍLICA}

estructurante del camino, los motivos del laberinto para expresar la perplejidad y la angustia ante una situación apremiante. La pérdida de las certidumbres e hitos familiares obliga al poeta a vivir un tiempo desazonado, y su herido vivir le hace más pesado su marginación, vive como "postergado / en un sopor errante» $\left(\mathrm{n}^{\circ} 542\right)$. Esta existencia precaria, menguada, inestable ha convertido al doliente poeta en un «hombre sin pauta» $\left(n^{\circ} 542\right)$ que vierte su queja en una lúcida constatación con los siguientes versos:

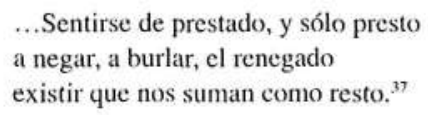

El desconcicrto nacido del desticrro y ese sentirse como en un envoltorio ajeno da lugar al obsesivo tema de la sombra, a una limpia radiografía de la sombra como dinámica de una escritura del exilio. Pasión de sombra se presenta como un conjunto homogéneo de 107 sonetos cual el diario íntimo de un hombre zarandeado que escudriña el horizonte de su malograda existencia. Surge entonce un patético diálogo consigo mismo, vertido las más veces en la segunda persona de singular, otras veces desde la primera persona introspectiva y excepcionalmemnete en la tercera que permite la maxima objetivación y la distancia meditativa (véase $\mathrm{n}^{\circ} 533$ ). El peso de la sombra como lastre existencial queda plasmado magníficamente desde cl soneto inaugural de Pasión de sombra:

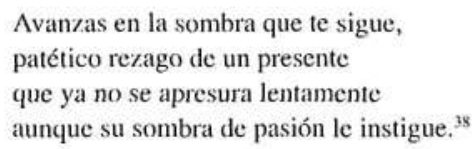

La originalísima voz de J. J. Domenchina radica en la elaboración de una poética de la enajenación que encuentra sus fundamentos en las figuras retóricas que manifiestan la dualidad. Así, la antítesis y el oximorón tienden a significar situaciones tensionales relacionadas con la sensación de extrañeza de un hombre que no encuentra su sitio y que busca desesperadamente una vía de salvación: «un presente / que ya no se apresura lentamente» $\left(n^{\circ} 454\right)^{39}$.

Sombra y cuerpo, camino y pisadas constituyen una densa red metafórica de manera permanente en la primera década del cxilio para significar la soledad y el desamparo, un caminar sin rumbo que en los momentos de desesperación muestra la inanidad de los esfuerzos para rescatar lo perdido.

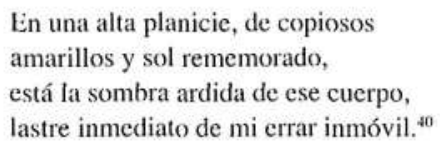

Pero la figura que más reiteradamente usa el poeta es el políptoton como si el juego de la derivación semántica proporcionase una vía de apropriación de una maltrecha y descompuesta identidad. El grado máximo de rendimiento de la figura lo alcanza J. J. Domenchina en el soneto fechado en el 25 de febrero con los malabarismos léxicos derivados del participio pasivo «puesto»:

Es ir, estar sin puesto, postergado

en un sopor errante, de traspuesto.

37.- Op. cit., $\mathrm{n}^{\circ} 542$, p. 119

38.- Op. cit., $\mathrm{n}^{\circ} 454$, p. 69.

39.- Los ejemplos de este tipo son muchos : «tu presencia de ausente» ( $\mathrm{n}^{\circ} 551$ ), «la ceniza de tu sombra quema» $\left(n^{\circ} 554\right)$.

40.- "Tercera elegía jubilar", op. cit., n 563-3, vv. 11-14, p. 198. 


\section{CLAUDE LE BIGOT}

Es presentirse marginal supuesto.

Es sentirse en falsilla, refalsado,

hombre sin pauta, de papel pautado,

que no se acuerda porque está mal puesto

en su memoria al día, de interpuesto-

con su acorde de ayer, desconcertado. ${ }^{41}$

Para ser más completo, convendría analizar, más detenidamente los sutiles efectos semánticos que surgen de la rima gramatical construida con el uso casi exclusivo de participios pasivos como en el soneto antecitado. Este caso viene acentuado por la reducción a dos rimas del conjunto del soneto; semejante modelo puede ser considerado como signo de la partición en la relación del poeta con su entorno. En efecto, la rima funciona sea como pauta de complementación (rima substantiva VS rima participial: -uto // -ado $\left(\mathrm{n}^{\circ} 544\right)$, sea como pauta de oposición (rima verbal VS rima participial: -oy // -ido ( ${ }^{\circ} 537$ ). Todo aquello muestra con creces la maestría de J. J. Domenchina como sonetista a la par que confirma una percepción dual y paradójica de su situación de exiliado cifrada en un vivir que es un no vivir.

De ahí tal vez surja una vía de salvación, cuando el poeta se somete al ascetismo de ver en su confinamiento una situación que lo libera de apostar por una ilusoria esperanza. Esta inversión de la lógica más convencional se nota en el soneto n 533 cuando Domenchina escribe:

\footnotetext{
No sentir el dolor equivaldría

a no vivir, a no sentirse vivo.

Estar entre las cosas, sin motivo,

$y$ ajeno a todo lo mortal, sería. ${ }^{42}$
}

A partir de lo que Domenchina llamará su «soledad suficiente», él edificará su soterraña existencia. Se esfuerza en mostrar la necesidad de su continuo dolor, pero no callándola sino haciéndola visible, presentable, o mejor dicho re-presentable. Si aún tiene validez la idea de que la escritura tiene una capacidad de conjuro, será porque la palabra cultiva la emoción, obliga a salirse de sí mismo, para dejar hablar lo vivido, lo sentido, lo visto. El mundo alrededor del exiliado se antropomorfiza en un re-dolor, en términos domenchinianos. De ahí, la nueva tierra de promisión, la otra orilla a la que puede pretender el poeta precario (según el concepto que usó Thélot ${ }^{43}$ apoyándose en el étimo precario / preces). Esta conciencia vivificante asoma ya con suficiente poder en el soneto $n^{\circ} 543$ :

\footnotetext{
Tu extenuación es lenta, tu premura

vertiginosa... Escribe tu agonía

-el esqueleto de tu muerte al día-,

porque te sobrevive tu escritura. ${ }^{4}$
}

Con mayor nitidez se reincide en una posible revitalización que permite la escritura en la conquista de una identidad propia:

...Como ceros

de luto, en papel frío, llevan, hueros

instantes, las palabras que no dices.

Bien está que te ocultes y deslices

en tu sombra; que vayas, en huideros

41.- Op. cit., $\mathrm{n}^{\circ} 542$, p. 119.

42.- Op. cit., $\mathrm{n}^{\circ} 533$, p. 114.

43.- Thélot Jérôme, La poésie précaire, Paris, PUF, 1997.

44.- Op. cit., n 541, p. 118. 


\section{TRES POETAS DEL 27 DESDE SU EXPERIENCIA EXÍLICA}

minutos enlutados, por senderos

propios, sin arrancarte las raíces. ${ }^{45}$

Se observará la presencia de la palabra clave en la poesía de posguerra, hasta el punto de alcanzar el rango de concepto en los análisis de Dámaso Alonso cuando habló de "poesía arraigada y desarraigada". Me limitaré a recordar que en el clásico estudio del crítico se establecía una oposición entre "poesía arraigada" y "poesía desarraigada", fuera del ámbito geográfico desde cl cual esta poesía fuera escrita. De modo que la oposición significaba o la presencia o la búsqueda de «centro o amarre», sea un lazo como se quiera considerar de tipo metafísico, histórico o teológico ${ }^{46}$.

A la terca voluntad de buscarse un centro, Domenchina sobrepone su lucha por el idioma; no sólo obedece a su afán de perfección formal sino a su deseo de mantener en su lenguaje tintes castizos, voces poco usitadas, neologismos que no registra el diccionario ${ }^{47}$. Todo aquello confirma un preciosismo que enlaza con el clasicismo purista del 27. También, habría que tomar en cuenta el uso de un repertorio estrófico que algunos componentes de la generación llevaron a su punto de perfección. Pero el virtuosismo de Domenchina en manejar la décima, la espinela, la sextilla, los tercetos encadenados, el soneto, demuestra una preocupación formal que conserva, incluso refuerza, el cánon purista, acaso reacio al proceso de mestizaje natural e inevitable que sc observará en otros poetas del exilio al filo de los años.

45.- Op. cit., $\mathrm{n}^{\circ} 475$, p. 81.

46.- $A$ la hora de examinar los posibles puentes entre la poesía española del exterior y del interior, convendría recordar el texto de D. Alonso, miembro de la generación del 27, autor del libro Hijos de la ira, en el cual se cifra «el contraste con toda poesía arraigada»: «Pero yo no estaba solo [...] sino una partícula de la doble angustia en que todos participábamos, la permuante y esencial en todo hombre, y la peculiar de esos ristes años de derrumbamiento, de catastrófico apocalispsis», en Poetas españoles contemporáneos, Madrid, Gredos, 1958 p. 349.

47.- Pueden consultarse listas exhaustivas en el trabajo de Antonio Carreira, « El gongorismo involuntario de Juan José Domenchina» in Bulletin hispanique, XC , $n^{\circ}$ 3-4, julio-dic., 1988, pp. 301-320. 